\title{
Lettucenin A and Its Role against Xanthomonas Campestris
}

\author{
Hong Chia Yean \\ School of Science and Technology, Universiti Malaysia Sabah \\ Locked Bag 2073, 88999 Kota Kinabalu, Sabah, Malaysia \\ Markus Atong \\ School of Sustainable Agriculture, Universiti Malaysia Sabah \\ Locked Bag 2073, 88999 Kota Kinabalu, Sabah, Malaysia \\ Tel: 6088-320-306 E-mail: xabex96@ums.edu.my \\ Khim Phin Chong (Corresponding author) \\ School of Sustainable Agriculture, Universiti Malaysia Sabah \\ Locked Bag 2073, 88999 Kota Kinabalu, Sabah, Malaysia \\ Tel: 6088-320-000 x5655Ｅ-mail: chongkp@ums.edu.my
}

\begin{abstract}
Lettucenin $\mathrm{A}$ is the major phytoalexin produced in lettuce after being elicited by biotic or abiotic elicitors. The production of lettucenin $\mathrm{A}$ in leaf can be induced by $5 \%$ of $\mathrm{CuSO}_{4}$ and $1 \%$ of $\mathrm{AgNO}_{3}$. A clear inhibition zone where the fungi Aspergillus niger failed to develop on TLC plates dipped in hexane: ethyl acetate $(1: 1, \mathrm{v} / \mathrm{v})$ at $\mathrm{R}_{\mathrm{f}} 0.45 \mathrm{was}$ observed. Lettucenin A was detected at a retention time of approximately $5.3 \mathrm{~min}$ after being injected into the HPLC run with isocratic solvent system containing water: acetonitrile ratio 60:40, (v/v). In vitro antibacterial study with Xanthomonas campestris results showed this pathogen has different sensitivity to all tested concentrations of lettucenin A. The bacteria was more sensitive to higher concentration of lettucenin A (333, 533 and $667 \mu \mathrm{g} \mathrm{ml} \mathrm{l}^{-1}$ ), compare to lower concentrations such as $67 \mu \mathrm{g} \mathrm{ml}^{-1}$. Thus, the relationship between the bacteria growth rate and lettucenin A concentration was negatively correlated. However, the bacteria growth rate continues to increase after two hours of incubation. Hence, it is suggested that $X$. campestris may have the ability to detoxify lettucenin A. The success or failure of $X$. campestris to invade lettuce may very well depend on the balance between accumulation and degradation of lettucenin A at the invading sites of lettuce. In summary, lettucenin A may play an important role in the resistance of lettuce against microbial colonization.
\end{abstract}

Keywords: Lactuca sativa, Lettucenin A, Xanthomonas campestris

\section{Introduction}

Lettuce (Lactuca sativa) is a member in the Family of Compositae or Asteraceae that is grown for its leaves, which are either eaten raw or cooked (Grubben and Sukprakarn, 1994). It is a popular type of vegetable consumed in Malaysia. The production of lettuce in Sabah, Malaysia increased from year 2002 to year 2003 (Department of Agriculture 2003 ${ }^{\mathrm{a}}$, $2003^{b}$ ) thus increasing exports from 1997 to 2000 (Jipanin et. al., 2001).

However, the growth of lettuce is always hampered by bacterial spots caused by Xanthomonas campestris pv. Vitians (Barak et. al., 2002). Plants being attacked by this pathogen developed symptoms like spots on leaves and thus decreasing its commercial value in the market. In Malaysia, farmers usually apply large quantities of chemical to control this disease, thus increasing the cost of production. Pesticides also caused contamination to soil, water and air which is hazardous to human health (Agrios, 2005; Barak et. al., 2002). New awareness to reduce the usage of chemical pesticides by developing alternative strategies or technologies in order to improve plant disease resistance and control of pathogens are being promoted.

On the other hand, there is a positive linear relationship between the amount and speed of accumulation of phytoalexin (secondary antimicrobial compound) produced and the degree of disease resistance. This relationship is also known as 
quantitative relationship. When there is a higher rate of phytoalexin accumulation, the smaller lesion size and lesser number of the bacterial cells is found in the host plant (Chong et. al., 2006 $6^{\mathrm{a}}$ 2006 ${ }^{\mathrm{b}}$; Chong et. al., 2007 ; Mansfield, $2000 ; 2007^{b}$ ). In this study, the role of lettucenin A was tested with different concentrations on Xanthomonas campestris to verify the antimicrobial effect of lettucenin A to X. campestris.

\section{Materials and Methods}

\subsection{Plant materials and pathogens culture}

Seeds of lettuce were sown in trays containing sterilized moistened soil at $25^{\circ} \mathrm{C}$. Later, three weeks-old seedlings were transferred from trays to pots. Elicitations were done when the plants reached eight weeks old. Aspergillus niger was kindly provided by Queen Elizabeth Hospital, Sabah and maintained on Potato Dextrose Agar (PDA) at $25^{\circ} \mathrm{C}$ in Plant Technology Laboratory of Universiti Malaysia Sabah. Xanthomonas campestris was obtained from Department of Agriculture, Tuaran, Sabah and maintained on Nutrient Agar (NA) at $25^{\circ} \mathrm{C}$.

\subsection{Elicitation and Extraction of lettucenin A}

Production of lettucenin A was induced with abiotic elicitors. Leaves of lettuce were elicited by spraying the leaves with $5 \%$ of $\mathrm{CuSO}_{4}$ or $1 \%$ of $\mathrm{AgNO}_{3}$. The leaves were incubated at $25^{\circ} \mathrm{C}$ for three days and then subjected to extraction by methanol $60 \%$ overnight. Extracts were filtered through Whatman No. 1 filter paper, pooled and evaporated with a rotary evaporation at $40-45^{\circ} \mathrm{C}$. Homogenates were re-extracted three times with chloroform, pooled and reduced to one $\mathrm{ml}$.

\subsection{Detection of lettucenin A and TLC Bioassays}

Thin Layer Chromatography (TLC) plates (Merck Kieselgel $60 \mathrm{~F}_{254}$ silica gel) were used throughout this study to detect the presence of antifungal properties of the leaf extracts and to separate lettucenin A from the crude extracts. The solvent system used was hexane: ethyl acetate $(1: 1, \mathrm{v} / \mathrm{v})$. Lettucenin A gives off a bright yellow florescence when examined under UV radiation with wavelength peak of $365 \mathrm{~nm}$. Chromatograms were sprayed with the conidia suspensions of Aspergillus niger in potato dextrose broth for bioassays. Replicated chromatogram plates were prepared and sprayed with 2,4-dinitrophenylhydrazine reagent (2,4-DNPH), which gave a pink coloration after reacting with lettucenin A. Retardation value $\left(\mathrm{R}_{\mathrm{f}}\right)$ for all bioactive and reactive bands were calculated and recorded.

\subsection{Isolation of Lettucenin A}

The confirmation of lettucenin A was based on the retention time $\left(\mathrm{R}_{t}\right)$ and UV absorption spectrum using High Performance Liquid Chromatography (HPLC) as described by Bennett et al., 1994. $10 \mu \mathrm{l}$ and $50 \mu \mathrm{l}$ of lettucenin A were injected into HPLC (Perkin Elmer Series 200), with SUPERCOCILTM LC-18 Analytical Column, $4.6 \mathrm{~mm}$ x $250 \mathrm{~mm}$, $5 \mu \mathrm{m}$. The presence of lettucenin A was analyzed using isocratic solvent system 60: $40(\mathrm{v} / \mathrm{v})$ water: acetonitrile running for $15 \mathrm{~min}$ at $25{ }^{\circ} \mathrm{C}$ with a flow rate of $1.0 \mathrm{ml} \mathrm{min}^{-1}$. The retention time $\left(\mathrm{R}_{\mathrm{t}}\right)$ for lettucenin $\mathrm{A}$ was recorded and compared with the $\mathrm{R}_{\mathrm{t}}$ as described by Bennett et. al., 1994.

\subsection{Quantification of lettucenin A}

From the replicated TLC plate, fluorescing band containing lettucenin A which had the same Rf value with the inhibition zone was marked by pencil, scraped out and eluted with $100 \%$ methanol. The tubes were spun at $12,000 \mathrm{rpm}$ using a centrifudge for five minutes. Supernatant containing lettucenin A was collected and subjected to spectrophotometry and HPLC. For estimation of lettucenin A concentration, a Cary 50 Bio UV-Visible Spectrophotometer was used and set to $446 \mathrm{~nm}$ wavelength, which is the maximum wavelength absorbance of lettucenin A (Takasugi et. al., 1985).

\subsection{Antibacterial activity of lettucenin A}

Different concentrations of lettucenin A $\left(67,200,333,533\right.$ and $\left.667 \mu \mathrm{g} \mathrm{ml}^{-1}\right)$, based on the amount recovered from TLC plates were prepared. Single colony of Xanthomonas campestris was transferred into petri dishes containing Nutrient Broth (NB). Initial optical density (OD) of the bacteria was measured by spectrophotometer at $600 \mathrm{~nm}$. The bacteria were incubated until the $\mathrm{OD}_{600}$ reading reached the range of 0.4-0.6 (Bacteria was in exponential stage). The bacteria within this range was tested throughout the study with different concentrations of lettucenin A in separate flask, and shaked at $220 \mathrm{rpm}$ using a rotary shaker. One $\mathrm{ml}$ of each different lettucenin A concentration was added into each flask with three replicates for each concentration tested. After incubated for half an hour, $\mathrm{OD}_{600}$ for each flask was measured and the procedures were repeated for the next one hour, 1.5 hours, two hours, 2.5 hours and three hours of incubation period. For control, lettucenin A was replaced by distilled water.

\section{Results and discussion}

\subsection{Detection of lettucenin A}

Lettucenin A accumulated after elicitation with $\mathrm{CuSO}_{4}$ and $\mathrm{AgNO}_{3}$, and it activities against Xanthomonas campestris, were studied. Lettucenin A gave a bright yellow fluorescence under UV radiation. In assessments of antifungal activity, 
lettucenin A was proven to inhibit the growth of Aspergillus niger at $\mathrm{R}_{\mathrm{f}} 0.45$. In addition, there were two other additional inhibition zones with the retention factor $R_{f} 0.80$ and 0.90 . Nevertheless, small and slightly inhibition zone was also observed in the control (Figure 1 (b)). Identification of lettucenin A was double confirmed after sprayed with the reagent 2,4-dinitrophenylhydrazine (2,4-DNPH). Lettucenin A displayed a pink coloration after sprayed with this reagent as illustrated in Figure 2. These bands had the retention value of 0.41 and they were not significantly different compared to the retention value that gave bright yellow fluorescence and strong antifungal activity in figure 1. Thus, this compound has been subsequently confirmed as lettucenin A. UV-spectrophotometer was used to scan the maximum absorbance. The maximum absorbance of lettucenin A in methanolic solution is at $446 \mathrm{~nm}$ (Figure 3) as described by Takasugi et al., 1985. The presence of lettucenin A was confirmed with HPLC based on the retention time $\left(\mathrm{R}_{\mathrm{t}}\right)$ as described by Bennett et al. 1994. Test was repeated twice with two different injection volumes, $10 \mu 1$ and $50 \mu l$. Both chromatograms had sharp peaks at $\mathrm{R}_{\mathrm{t}}$ approximately $5.3 \mathrm{~min}$ although the second injection volume was five fold higher (Figure 4). An arrow indicated that the peaks correspond to lettucenin A.

\subsection{Antibacterial Activity of Lettucenin A}

$X$. campestris showed different responses after exposure to lettucenin A. Bacteria growth rates were significant lower for those exposed to lettucenin $\mathrm{A}$ in comparison to the control experiment. $X$. campestris were sensitive to all concentrations of lettucenin A, at least, at the first 1.5 hours of incubation period. However, growth rates of treated bacteria were not significantly different compared to the control experiment when the duration of the experiments was extended to 2.0, 2.5 and 3.0 hours incubation period (Figure 5). For bacteria treated with $67 \mu \mathrm{g} \mathrm{ml} \mathrm{l}^{-1}$ of lettucenin A, the growth rate was significantly lower in comparison to the control experiment at 0.5 and 1.5 hours, where the growth rate was 0.157 and 0.192 , respectively. For other concentrations, the bacteria growth rate was significantly lower compared to control experiment. However, the growth rates of treated with lettucenin A were not significant in comparison to the control experiment at 2.0, 2.5 and 3.0 hours of incubation period, except for concentration of 333,533 and $667 \mu \mathrm{g} \mathrm{ml}{ }^{-1}$ at 2.5 hours.

In vitro study showed a negative correlation between the concentrations of lettucenin A and the growth rate of pathogen $X$. campestris. Higher concentration of lettucenin A had a better inhibitory effect to the growth of $X$. campestris. But the bacteria growth was also inhibited in the lowest concentration tested; $67 \mu \mathrm{g} \mathrm{ml}^{-1}$. However, growth of $X$. campestris was more effectively restricted by higher concentration of lettucenin A $\left(333,533\right.$ and $\left.667 \mu \mathrm{g} \mathrm{ml}{ }^{-1}\right)$. The effect of lettucenin A against bacteria at the concentration of 333, 533 and $667 \mu \mathrm{g} \mathrm{ml}^{-1}$ was not significant among each other.

In other words, concentration of $333 \mu \mathrm{g} \mathrm{ml}^{-1}$ maybe strong enough to restrict the bacteria growth. In most cases, higher concentrations of lettucenin A $\left(333,533\right.$ and $\left.667 \mu \mathrm{g} \mathrm{ml}^{-1}\right)$ were more effective against the bacteria. Different concentrations of lettucenin A had different effects on the growth of $X$. campestris. Thus, differences in the resistance and susceptibility of lettuce to $X$. campestris may associate with different concentrations of lettucenin A accumulated, as well as the speed of accumulation around the invading tissue. Localization of lettucenin A where this compound was concentrated in dead and infection sites provides good evidence in indicating the role of lettucenin A against pathogen $X$. campestris.

Besides that, the onset of hypersensitive reaction (HR) is always associated with rapid phytoalexins production. Phytoalexins were found localized to cells that had undergone HR. Fungal or bacterial invasion are then restricted in the HR cells. Accumulation of phytoalexins at the right time and place is very important parameter to cause cessation and restriction to microbial growth. After two hours of incubation, the growth of bacteria was not significant to control. This phenomenon occurred most probably because $X$. campestris may have the ability to detoxify the lettucenin A after the first 1.5 hours. Lettucenin A may be degraded by the bacteria into less toxic compounds. The ability of the bacteria to detoxify host's phytoalexin is an important determinant of pathogenicity (Kuc, 1995; Mansfield, 2000; Purkayastha, 1995; vanEtten et. al., 1989). In other words, the antibacterial action of lettucenin A is considered as bacteriostatic.

Other examples of phytoalexin detoxification were proposed in the in vitro relationship of Botrytis cineria, B. fabae with metabolism of wyerone, wyerone acid and wyerone epoxide of broad bean (Vicia faba). Detoxification of wyerone and wyerone epoxide was founded preceding the onset of germ-tube growth of both $B$. cineria and $B$. fabae; whereas production of secondary germ tubes from surviving conidia and sub-apical was occurred without comparable metabolism of wyerone acid. The concentration of wyerone was unlikely to decrease during the fungal-phytoalexin interaction (Rossall and Mansfield, 1984; Rossall et. al., 1980)).

Detoxification of phytoalexin by bacteria was also described in the in vivo relationship between cotton (Gossypium spp.) and bacteria Xanthomonas campestris pv. malvacearum. Cotton phytoalexins, 2,7-dihydroxycadalene (DHC) was decomposed to lacinilene $\mathrm{C}$ ( $\mathrm{LC}$ ) while desoxyhemigossypol (dHG) was decomposed to hemigossypol (HG). Inhibition or toxicity occurred only for the first two hours of exposure to the phytoalexins. Growth rates of X. campestris pv. malvacearum were similar to the control in the following incubation period (Abraham et. al., 1999). 
The amount of phytoalexin accumulated depends on the rate and duration of phytoalexin synthesis, which will be affected by the speed where cells are killed by the invasion pathogens and the ability to tolerate and degrade the phytoalexin (Mansfield, 2000). Thus, in vivo, the invasion of lettuce by X. campestris is regulated by the balance between rates of synthesis of lettucenin $\mathrm{A}$ and the accumulation in the plant and the degradation of that compound by the bacteria within infection tissues (Bennett et. al., 1994). Low concentration of lettucenin A would be produced at the beginning of the interaction. If $X$. campestris is tolerant and possess the enzymic capacity to detoxify lettucenin A, it will able to grow and detoxify higher concentration of lettucenin A and kill more cells. In this case, $X$. campestris is said to be pathogenic and the invaded lettuce is susceptible to it. If the bacterium is sensitive to lettucenin A, higher concentration of lettucenin A may produce at the infection site and thus inhibiting the further invasion of the bacterium. In this case, $X$. campestris is said to be non-pathogenic and the lettuce is tolerant to it (Bennett et. al., 1994).

\section{Conclusion}

In vitro activity showed that the bacteria was more sensitive to higher concentration of lettucenin A such as 333,533 or $667 \mu \mathrm{g} \mathrm{ml}^{-1}$ than lower concentration such as $67 \mu \mathrm{g} \mathrm{ml}^{-1}$. There was a negative correlation between the concentrations of lettucenin A and the growth rate of the bacteria. However, after two hours of incubation period, the bacteria is suspected to have the ability to detoxify lettucenin A because the growth of bacteria was continuous. Lettucenin A is believed to have a role in the resistance of lettuce to microbial colonization in a sufficient concentration and at the right time. However, the exact concentration of lettucenin A that would inhibit the growth of pathogen Xanthomonas campestris under natural condition needs further study.

\section{Acknowledgments}

The authors wish to extend their highest appreciation to Prof. Dr. Ridzwan Abd Rahman, the Dean, School of Sustainable Agriculture, Universiti Malaysia Sabah for his supports and advices throughout the study. Also to Mr. Collin G. Joseph for giving comments on this article.

\section{References}

Abraham, K.J., Pierce, M.L., \& Essenberg, M. (1999). The phytoalexins desoxyhemigossypol and hemigossypol are elicited by Xanthomonas in Gossypium cotyledons. Phytochemistry, 52, 829-836.

Agrios, G.N. (2005). Plant pathology. $5^{\text {th }}$ Ed. Elsevier Academic Press, Amsterdam.

Barak, J.D., Koike, S.T., \& Gilbertson, R.L. (2002). Movement of Xanthomonas campestris pv. vitians in the stems of lettuce and seed contamination. Plant Pathology, 51, 506-512.

Bennett, M.H., Gallagher, M.D.S., Bestwick, C.S., Rossiter, J.T., \& Mansfield, J.W. (1994). The phytoalexin response of lettuce to challenge by Botrytis cinerea, Bremia lactucae and Pseudomonas syringae pv. phaseolicola. Physiological and Molecular Plant Pathology, 44, 321-333.

Chong, K.P., Kee, K. C., \& Desyi. A. N. $\left(2007^{\mathrm{a}}\right)$. Comparison of Aging Effect on Accumulation of Sakuranetin in Paddy and Camalexin in Arabidopsis thaliana after Elicited by Silver Nitrate. Asian Journal of Microbiology Biotechnology and Environmental Sciences, 9, 463-467.

Chong, K.P., Mansfield, J. W., Bennett, M. H., \& Rossiter, J. F. $\left(2006^{\mathrm{a}}\right)$. Camalexin Accumulation in Arabidopsis Leaves Challenged by Botrytis cinerea. Journal of Borneo Science, 19, 66-74.

Chong, K.P., Mansfield, J. W., Bennett, M. H., \& Rossiter, J. F. $\left(2007^{b}\right)$. In vitro antifungal and fungitoxicity of camalexin from Arabidopsis thaliana against Botrytis cinerea. Asian Journal of Microbiology Biotechnology and Environmental Science. 9(3), 649-655.

Chong K.P., Mansfield, J. W., Bennett, M. H. and Rossiter, J. F. $\left(2006^{b}\right)$. Detection of antifungal compounds in Arabidopsis thaliana and Brassica oleracea by Thin Layer Chromatography. ASEAN Journal on Science and Technology for Development, 23(1\&2), 123-131.

Cruickshank, I.A.M. (1963). Phytoalexins. Annual Review of Phytopathology, 1, 351-374.

Department of Agriculture, Sabah. (2003a). Keluasan Tanaman Mengikut Bahagian dan Jenis Tanaman, Sabah 2002. [Online] Available: http://www.sabah.gov.my/tani/Perangkaan/Perangkaan2002.pdf (in malay language).

Department of Agriculture, Sabah (2003b). Keluasan Tanaman Mengikut Bahagian dan Jenis Tanaman, Sabah 2003. [Online] Available: http://www.sabah.gov.my/tani/Perangkaan/Perangkaan2003.pdf (in malay language).

Grubben, G.J.H. \& Sukprakarn, S. (1994). Alphabetical treatment of species: Lactuca sativa. In: Siemonsma, J.S. \& Piluek, K. (eds.). Plant resources of South-East Asia:Vegetables 8. Prosea Foundation, Bogor, pp. 186-190.

Hammerschmidt, R. (1999). Phytoalexins: What have we learned after 60 years? Annual Review of Phytopathology, 37, 285-306. 
Jipanin, J., Rahman, A.A., Jaimi, J.R. \& Phua, P.K. (2001). Management of pesticide use on vegetable production: Role of Department of Agriculture Sabah. Proceedings of the Sixth Sabah Inter-Agency Tropical Ecosystem (SITE) Research Seminar, 13-14 September 2001, Kota Kinabalu, Sabah, pp. 63-85.

Kuć, J. (1995). Phytoalexins, stress metabolism, and disease resistance in plants. Annual Review of Phytopathology, 33, 275-297.

Mansfield, J.W. (2000). Antimicrobial compounds and resistance: the role of phytoalexins and phytoanticipins. In: Slusarenko, A.J., Fraser, R.S.S. \& van Loon, L.C. (eds.). Mechanisms of Resistance to Plant Diseases. Kluwer Academic Publishers, Netherlands, pp. 325-370.

Purkayastha, R.P. (1995). Progress in phytoalexin research during the past 50 years. In: Daniel, M. and Purkayastha, R.P. (eds.). Handbook of phytoalexin metabolism and action. Marcel Dekker Inc., New York, pp. 1-39.

Rossall, S. \& Mansfield, J.W. (1984). Relationships between germ-tube growth by Botrytis cinerea and B.fabae and their metabolism of the phytoalexins wyerone, wyerone acid and wyerone epoxide. Transactions of the British Mycological Society, 82, 571-576.

Rossall, S., Mansfield, J.W., \& Hutson, R.A. (1980). Death of Botrytis cinerea and B. fabae following exposure to wyerone derivatives in vitro and during infection development in broad bean leaves. Physiological Plant Pathology, 16, $135-146$.

Takasugi, M., Okinaka, S., Katsui, N., Masamune, T., Shirata, A., \& Ohuchi, M. (1985). Isolation and structure of lettucenin A, a novel guaianolide phytoalexin from Lactuca sativa var. capitata (Compositae). Journal of the Chemical Society, Chemical Communications, 10, 621-622.

VanEtten, H.D., Matthews, D.E., \& Matthews, P.S. (1989). Phytoalexin detoxification: Importance for pathogenicity and practical implications. Annual Review of Phytopathology, 27, 143-164.
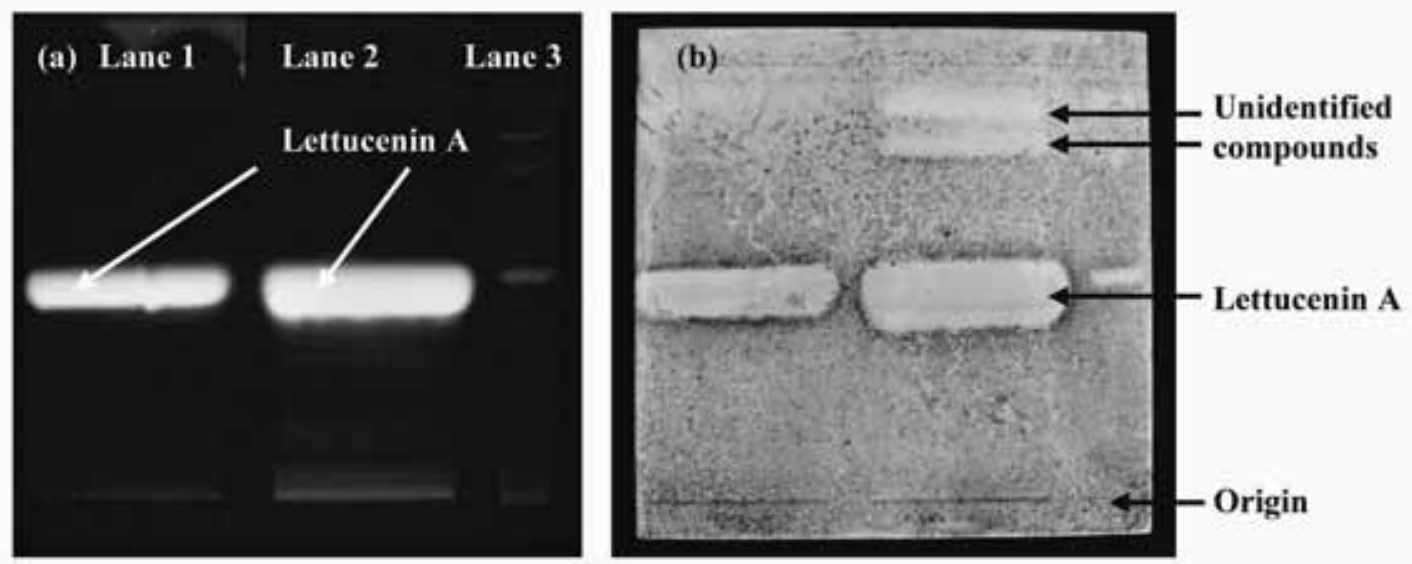

Figure 1. Chromatograms of leaf extracts developed in hexane: ethyl acetate $(1: 1, \mathrm{v} / \mathrm{v})$ as the solvent system. Lane 1 : lettuce elicited with 5\% $\mathrm{CuSO}_{4}$; Lane 2: lettuce elicited with 1\% $\mathrm{AgNO}_{3}$ and Lane 3: control.

(a) Observation under UV $365 \mathrm{~nm}$ wavelength (b) bioassay with Aspergillus niger. 


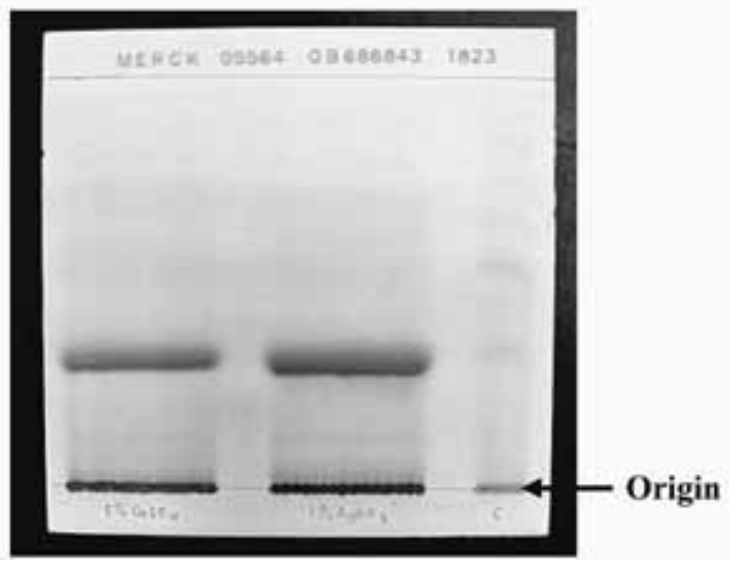

Figure 2. Chromatogram of lettuce extracts after elicited with (a) $5 \%$ of $\mathrm{CuSO}_{4}\left(\mathrm{w} / \mathrm{v}\right.$ ) and (b) $1 \% \mathrm{AgNO}_{3}$ and sprayed with reagent 2,4-dinitrophenylhydrazine (2,4-DNPH).

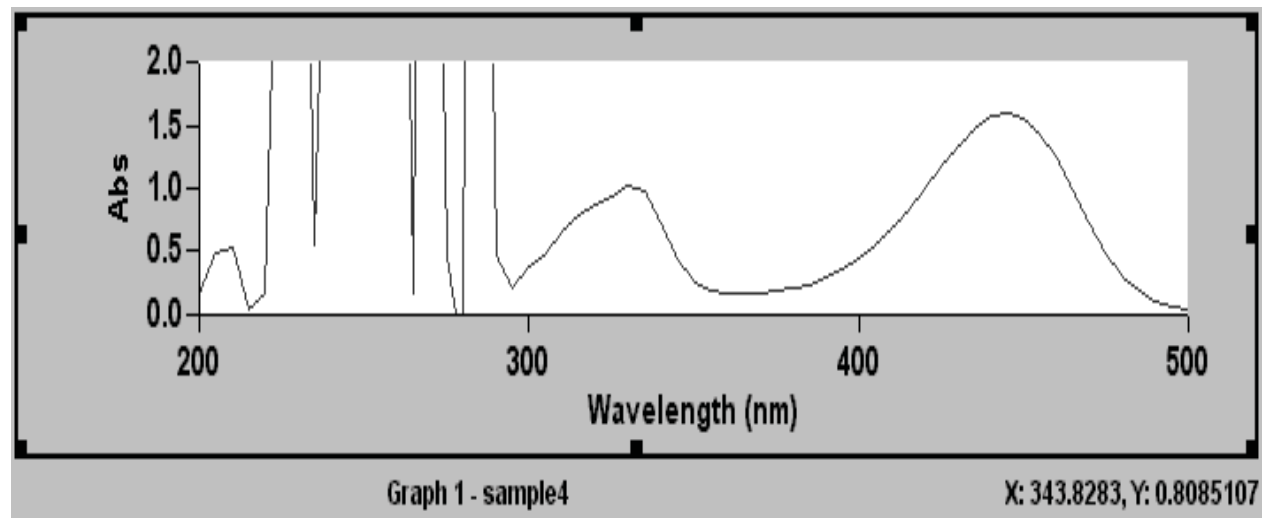

Figure 3. Ultraviolet absorption spectrum of lettucenin A range from 200-500 nm wavelengths in methanolic solution.

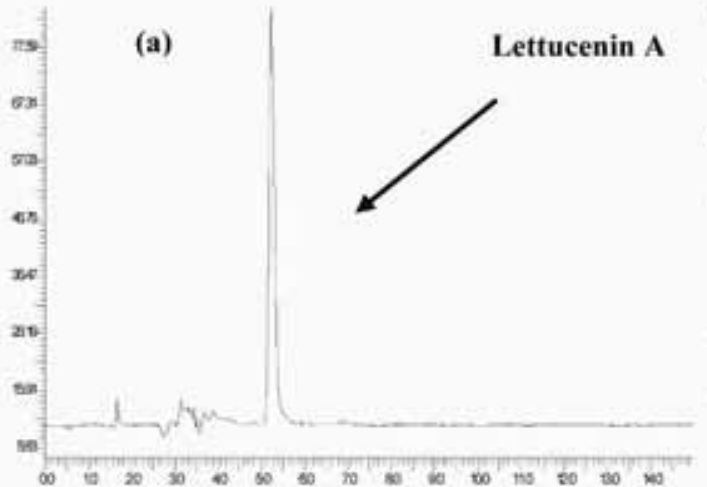

Retention time (b)

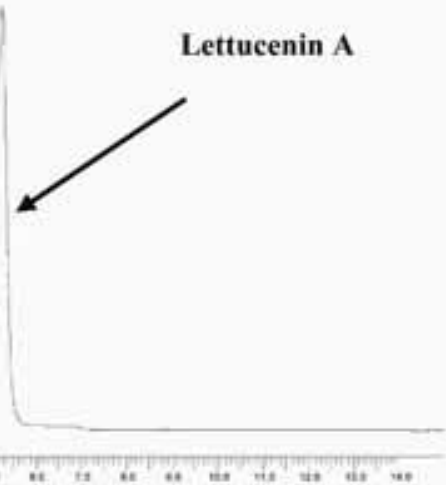

Retention time

Figure 4. HPLC chromatograms at $446 \mathrm{~nm}$ excitation showing the presence of lettucenin A in (a) $10 \mu \mathrm{l}$ and (b) $50 \mu 1$ volume of injection. 


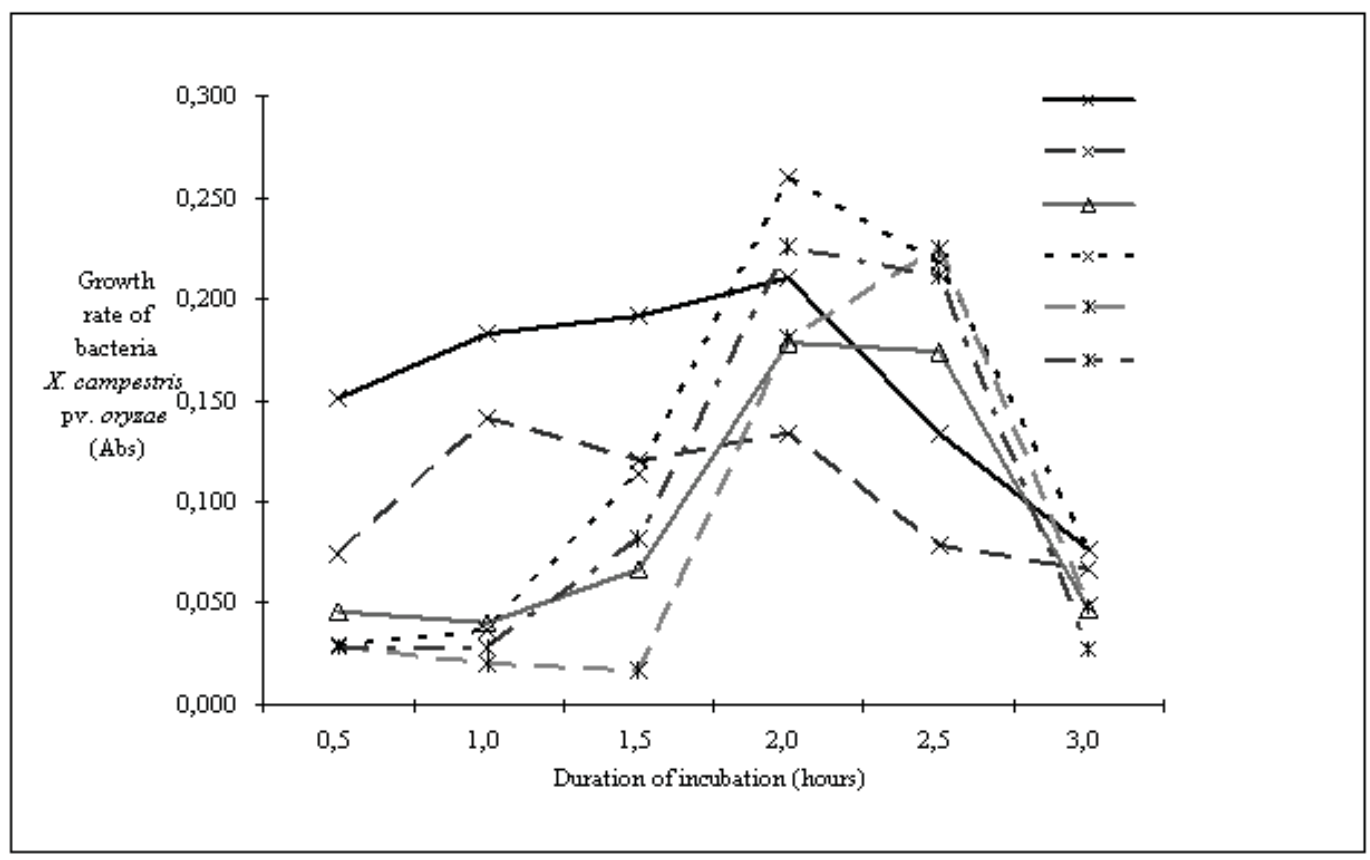

Figure 5. Comparison of growth rate of X. campestris in five different concentrations of lettucenin A for three hours of incubation. 